

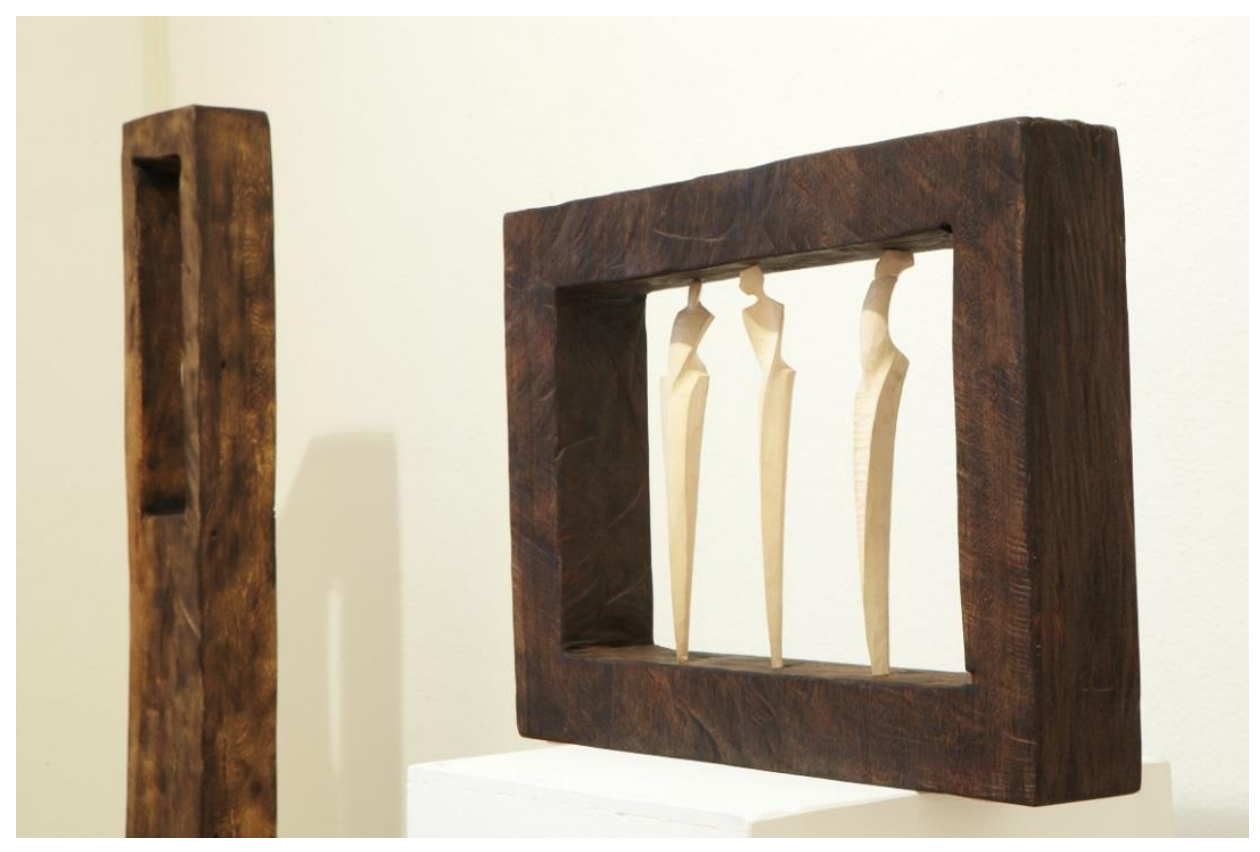

\title{
Warum guckt der so wie er guckt?
}

\section{Martin Schonhardt Bildhauer}

\author{
MARTIN SCHONHARDT BILDHAUER TALSTR. 51 D-79263 \\ SIMONSWALD
}

FON 076831667 BILDHAUER.SCHONHARDT@T-ONLINE.DE WWW:BILDHAUER-SCHONHARDT.DE 


\section{Warum guckt der so wie er guckt?}

Mit diesen tiefen badischen Worten fragte mich ein Besucher meiner Werkstatt nach dem Ausdruck einer meiner Figuren. „Gute Frage“, antwortete ich Ihm.

Weil ich die Figur so erlebt habe. In meine Gedanken ist sie so entstanden. Kein personifizierter Typ, nein die Summe aus Erlebten kommt hier zum Ausdruck. Wenn ich hier in meiner Werkstatt in einem tiefen Schwarzwald Tal arbeite dann kommen sie so zum Vorschein. Die Bruddler, die Fröhlichen, die Ästheten, die Zornigen, die Verzweifelten, die Frischverliebten und alle Anderen auch. Immer wieder nehme ich etwas mit von meinen Streifzügen durch die Menschheit und es ist noch kein Ende in Sicht.

Kernpunkt meiner Skulpturen ist das Thema Mensch.

Die Auseinandersetzung des Menschen mit seiner Umgebung bietet so viele Facetten, gesellschaftlich, seelisch, wörtlich und räumlich, dass ich mich dauernd herausgefordert sehe, diese Beobachtungen umzusetzen.

Inhaltlich zeigt sich diese Auseinandersetzung in verschiedenen Themenbereichen wieder. Meine, oft nur durch spartanische Bewegung ausgestatteten Skulpturen sollen etwas von diesen Fragen und Beobachtungen aufnehmen und weitergeben.

Vielleicht entdecken Sie ein Stück von sich. Erschrecken Sie nicht, sondern nehmen Sie Ihren Teil mit.

Formal erscheint diese Auseinandersetzung in der Anwendung verschiedener Materialien, derer Kombination und den notwendigen Eingriffen zur Artikulierung der Form und ihrer Aussage.

Die Erforschung von Raum und Material als dauernder Prozess sind Antriebsfeder des künstlerischen Arbeitens. 
Ausstellung Waldkirch 2011

Auf den Punkt gebracht 


\section{BDH Klinik Elzach Stehende Frau \\ 2013}

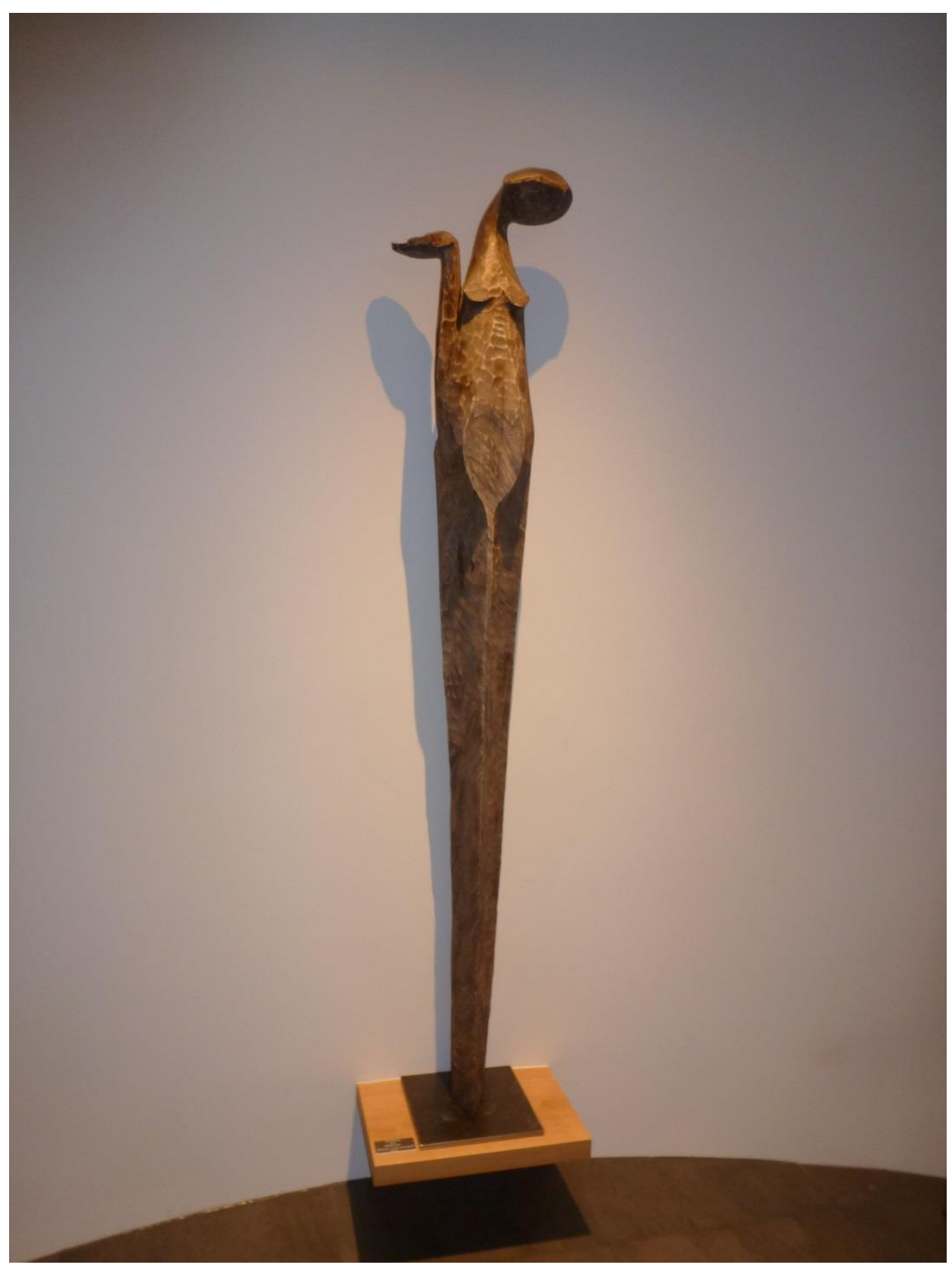


Emotion

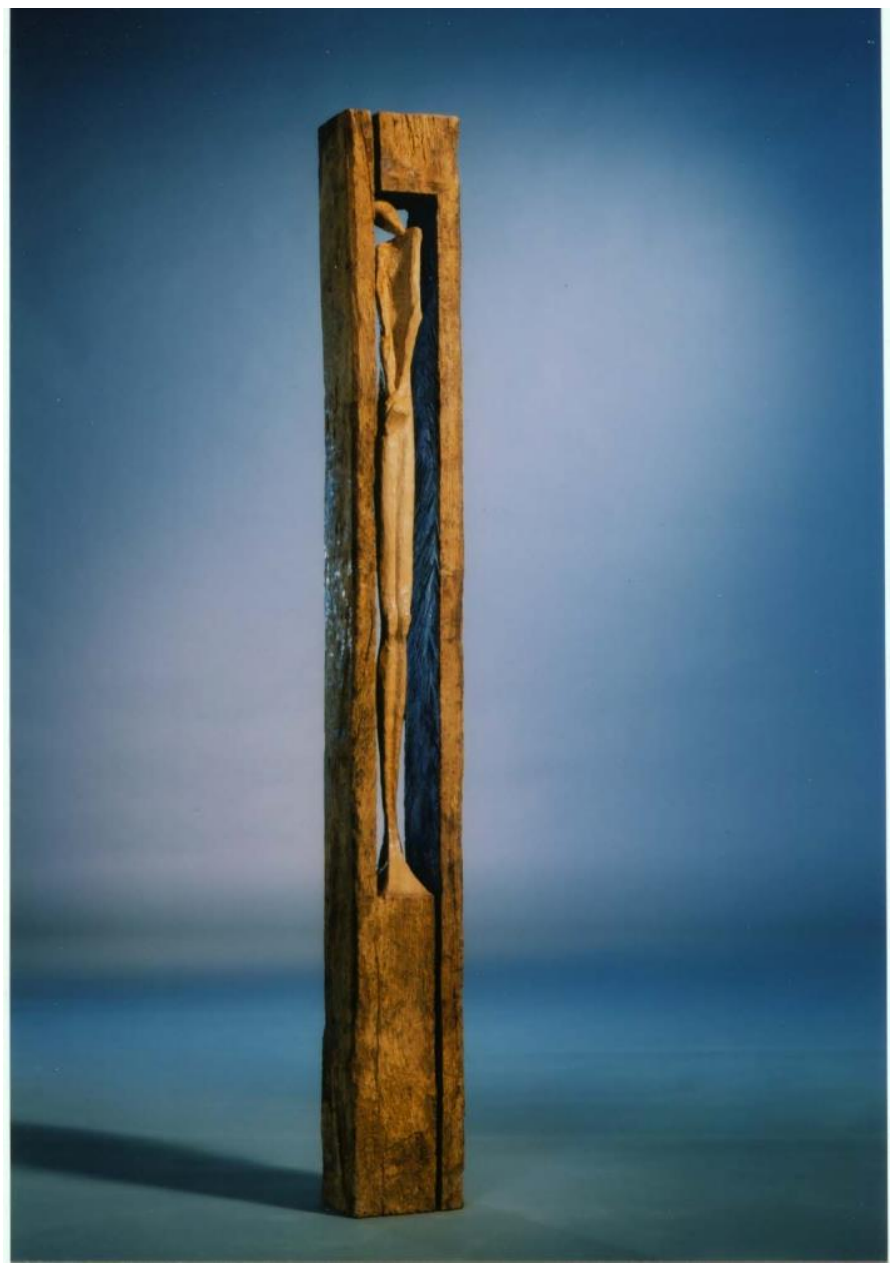




\section{Junges Fräulein verlegen 2015}

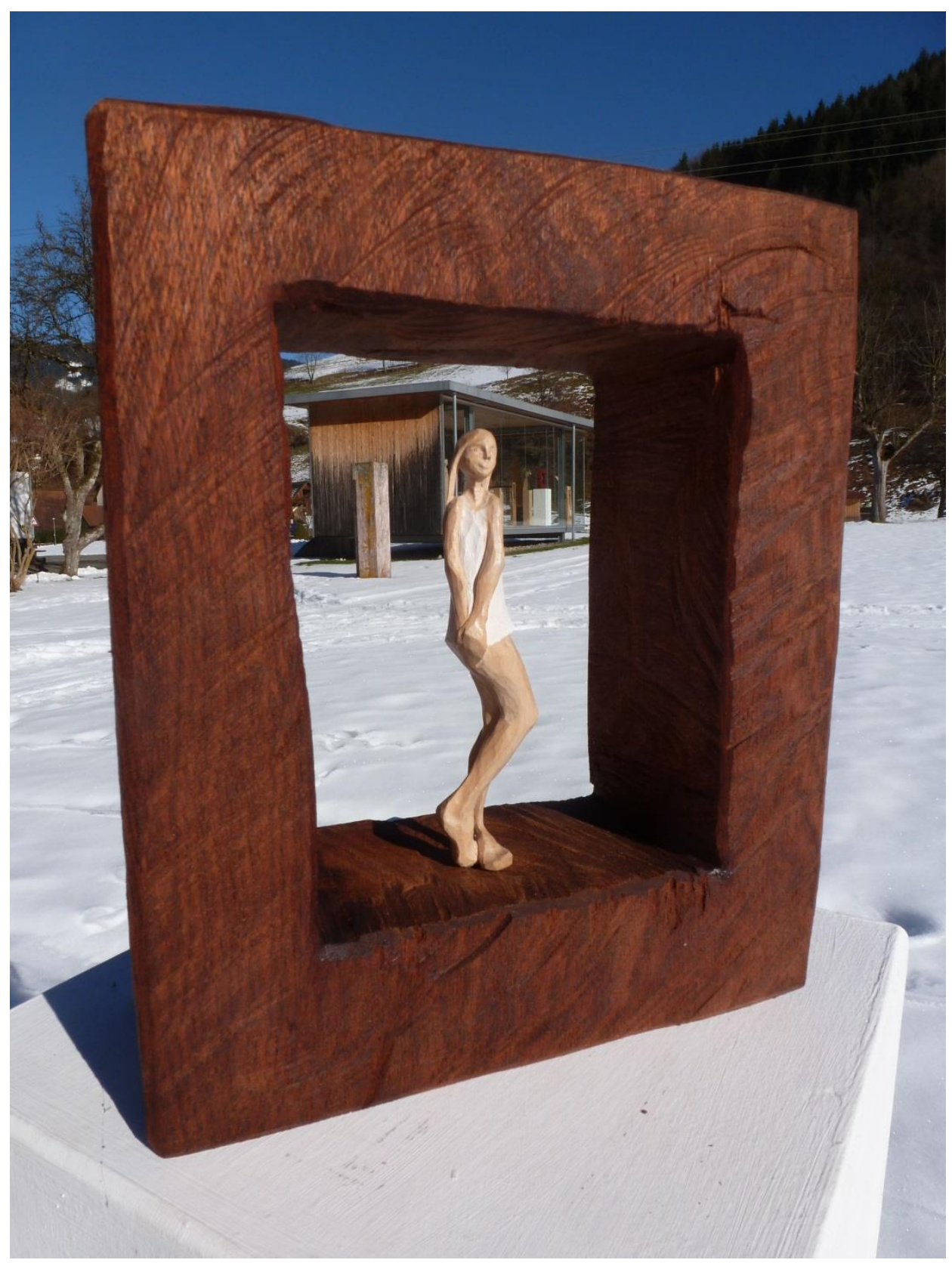




\section{Skulptur Begegnung 11}

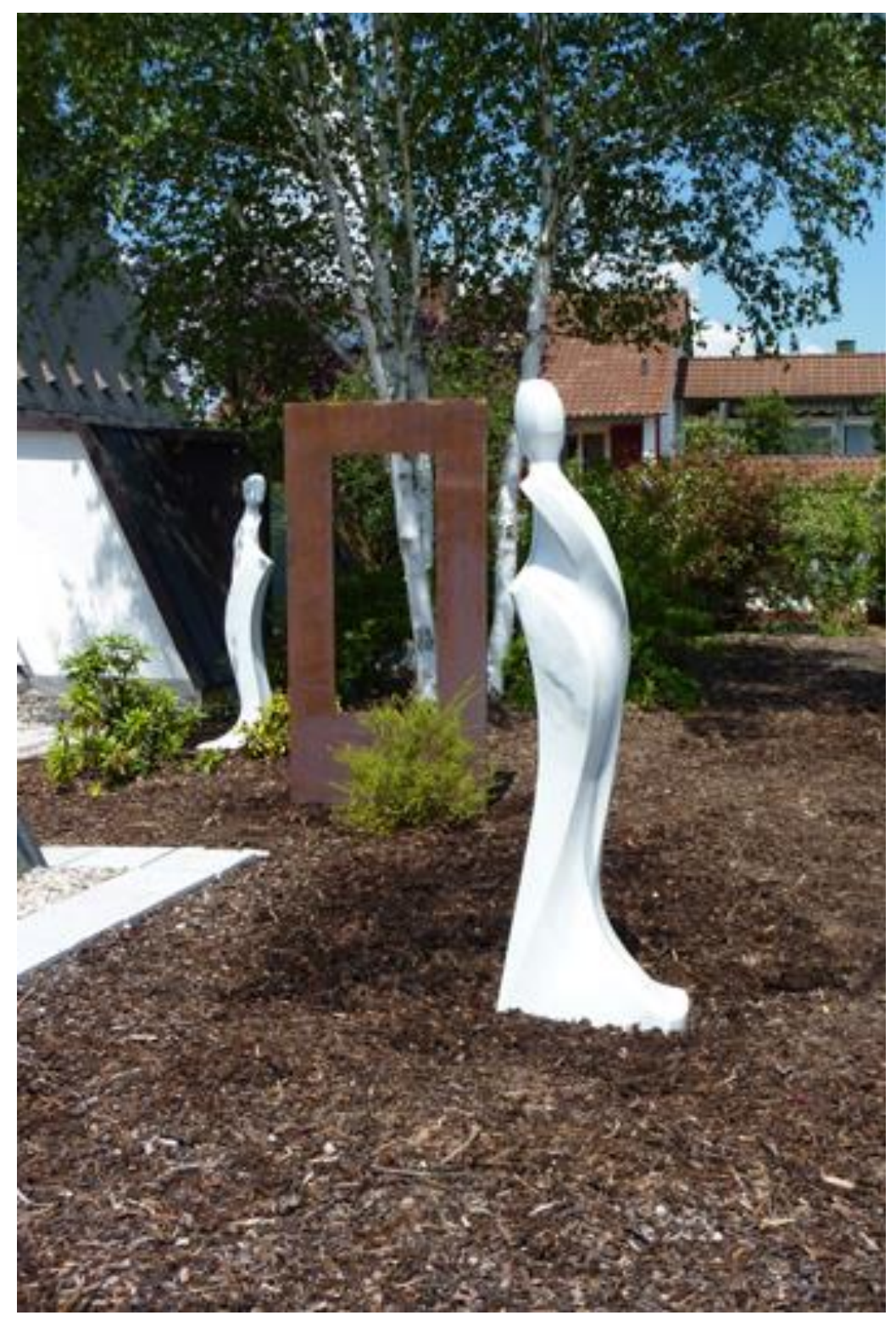


Skulptur Gehen I

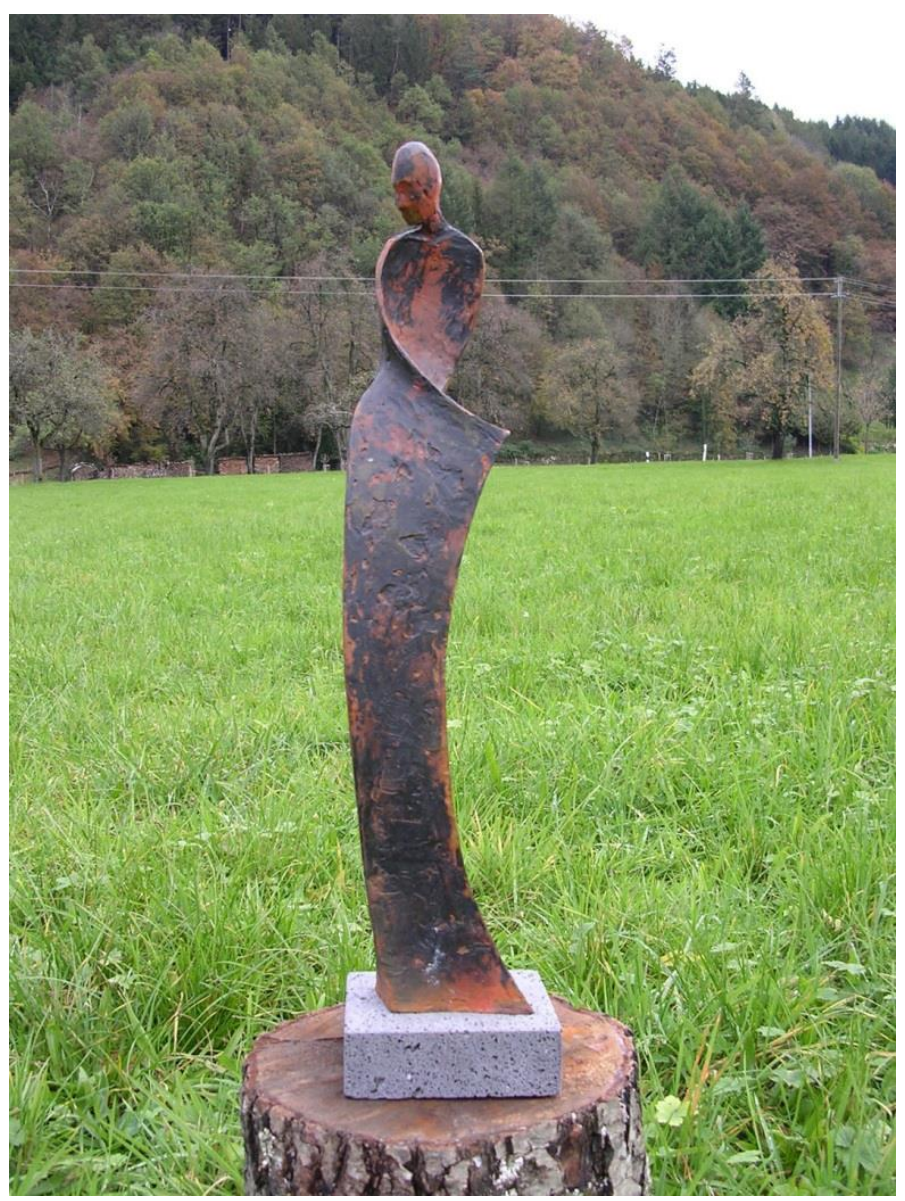




\section{Skulptur Kommen I}

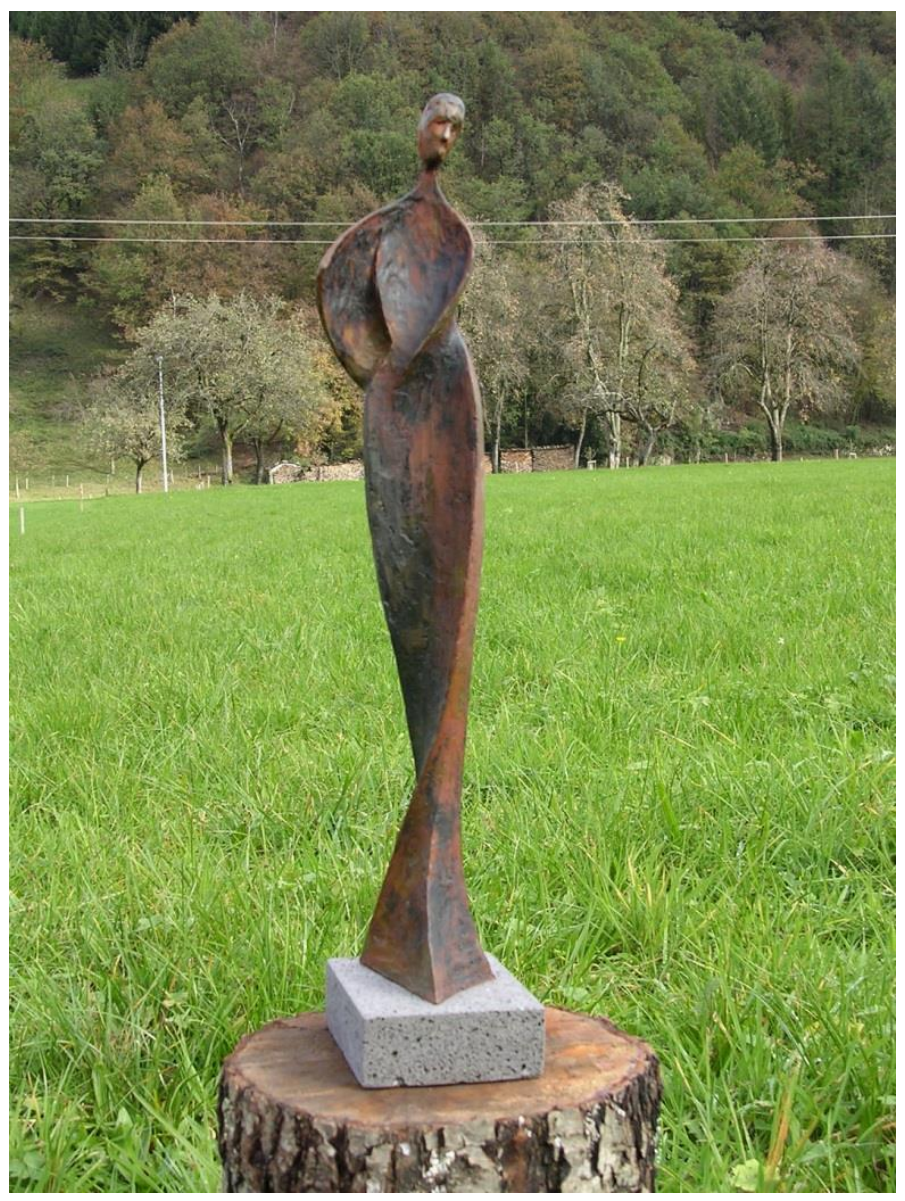

